\title{
Massive Pulmonary Embolism Following Varicose Vein Surgery That Was Successfully Treated with Thrombolytic Therapy
}

\author{
Ayse Baha ${ }^{1}$, Reshat Mehmet Baha ${ }^{2}$, Volkan Eroglu ${ }^{3}$, \\ Aysegul Logoglu ${ }^{4}$ and Yahya Kemal Icen ${ }^{2}$
}

\begin{abstract}
The risk of massive pulmonary thromboembolism (PTE) secondary to varicose vein surgery is very low. There are only two cases which have been reported regarding massive PTE occurring after varicose vein surgery. We herein present the case of a woman who had suffered from chest pain. A short period following her admission to the emergency department, she had cardiac arrest and was subsequently diagnosed with massive PTE. Thrombolytic therapy was administered and her clinical status dramatically improved thereafter. Massive PTE may occur after minor surgical procedures, and thrombolytic therapy can safely be administered after cardiopulmonary resuscitation.
\end{abstract}

Key words: massive pulmonary thromboembolism, varicose vein surgery, thrombolytic therapy

(Intern Med 55: 1907-1910, 2016)

(DOI: 10.2169/internalmedicine.55.5068)

\section{Introduction}

Major surgery is the most important risk factor of venous thromboembolism (VTE) (1). On the other hand, its risk after minor surgery is even lower and the risk of VTE following varicose vein surgery is known to be very low $(2,3)$. Two cases have been reported in the literature regarding massive pulmonary thromboembolism (PTE) occurring after varicose vein surgery that were treated with thrombolytic therapy. According to an expert opinion, it is safe to use thrombolytic therapy for patients who had cardiac arrest secondary to massive PTE (2). In such patients, it is lifesaving to start thrombolytic treatment as soon as possible (4). We herein present the dramatic clinical improvement of a patient due to successful treatment with thrombolytic therapy who had cardiac arrest secondary to massive PTE following varicose vein surgery.

\section{Case Report}

A 47-year-old woman with a history of right lower limb varicose vein surgery 7 days previously was admitted to the emergency department with squeezing chest pain that was present for 3 days. She had been followed for hypertension and depression, she was a nonsmoker and her family history was nonspecific. A short period following her admission, she had cardiac arrest and after approximately 3-minute resuscitation, sinus rhythm was obtained. The patient was then intubated and her vital signs were as follows: body temperature of $36.8^{\circ} \mathrm{C}$, arterial blood pressure of $70 / 50 \mathrm{mmHg}$ and heart rate 138/min. Thorax computerized tomography (CT) was planned with the prediagnosis of massive PTE due to the patient's history of recent surgery and shock status. Bedside echocardiography, which was performed to rule out potential accompanying pathologies, revealed increased right chamber sizes and pulmonary hypertension [systolic pulmonary artery pressure $(\mathrm{SPAP})=55 \mathrm{mmHg}]$. CT revealed bilat-

\footnotetext{
${ }^{1}$ Department of Pulmonary Medicine, Osmaniye National Hospital, Turkey, ${ }^{2}$ Department of Cardiology, Osmaniye National Hospital, Turkey, ${ }^{3}$ Department of Anesthesiology, Osmaniye National Hospital, Turkey and ${ }^{4}$ Department of Emergency Medicine, Osmaniye National Hospital, Turkey

Received for publication February 4, 2015; Accepted for publication October 19, 2015

Correspondence to Dr. Ayse Baha, dr_aysedemir@hotmail.com
} 


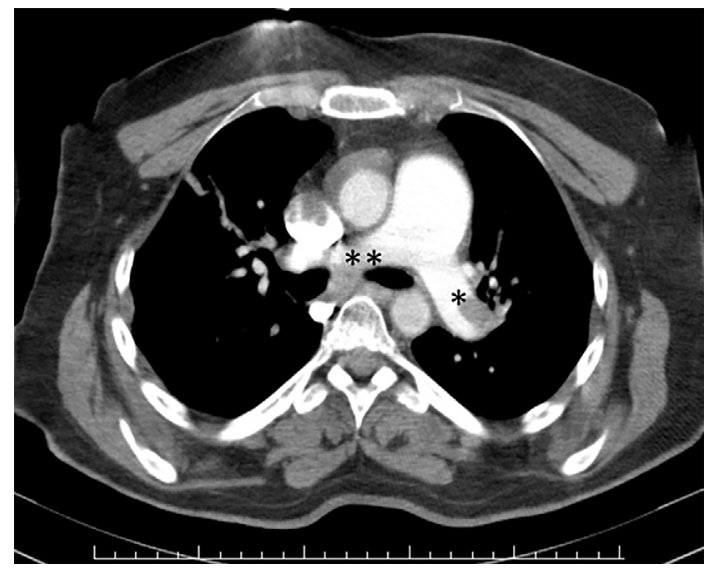

Figure 1. Thorax computerized tomography (CT) revealing thrombi in the main pulmonary arteries (*: left pulmonary artery, **: right pulmonary artery).

eral thrombi in the main pulmonary arteries, confirming our diagnosis (Fig. 1, 2). Immediately after she was admitted to the intensive care unit (ICU), she had second cardiac arrest, and sinus rhythm was obtained after 5-minutes resuscitation. Noradrenalin infusion was started at a $10 \mathrm{mcg} / \mathrm{kg} / \mathrm{min}$ infusion rate due to hypotension, and her oxygen saturation was between $90-92 \%$ with $80 \%$ oxygen supply given via a mechanical ventilator. A hemogram revealed a hemoglobin value of $12.0 \mathrm{~g} / \mathrm{dL}$, platelet count of $195 \times 10^{3} / \mu \mathrm{L}$ and $\mathrm{d}-$ dimer concentration of $4 \mathrm{ng} / \mathrm{mL}$ (normal range: $0-0.5 \mathrm{ng} /$ $\mathrm{mL}$ ). After the patient's relative provided informed consent for thrombolytic therapy, an intravenous infusion of $100 \mathrm{mg}$ alteplase for 2 hours was started. Shortly after thrombolytic therapy, unfractionated heparin (UFH) infusion at a rate of $18 \mathrm{U} / \mathrm{kg} / \mathrm{hr}$ was started and its dose was adjusted according to activated partial thromboplastin time (aPTT) levels that were checked at least 4 times daily. Six hours after thrombolytic treatment, the patient regained consciousness and responded to verbal stimuli; there was no longer need for the noradrenalin infusion after 8 hours, and she was extubated 24 hours after the initiation of thrombolytic treatment. Warfarin therapy was started at 24 hours from the start of UFH infusion. Due to difficulties in maintaining target aPTT levels, UFH was switched to subcutaneous enoxaparin sodium given at the dose $0.01 \mathrm{~mL} / \mathrm{kg}$ twice daily. Approximately 30 hours from the start of thrombolytic treatment, the patient's oxygen saturation at room air was over $95 \%$, her hemodynamic status was stable and she was discharged from the ICU and taken to a room in the pulmonology department. On the 6th day of hospitalization, SPAP measured via echocardiography was decreased to $35 \mathrm{mmHg}$. Bilateral lowerextremity venous Doppler ultrasonography revealed a thrombus in the right vena saphena parva, and deep veins were clearly noted bilaterally. The underlying factor contributing to massive PTE was thought to be varicose vein surgery, which had been performed 7 days prior to her admission. After maintaining target INR levels on 2 consecutive days, enoxaparin sodium was discontinued. The patient was then

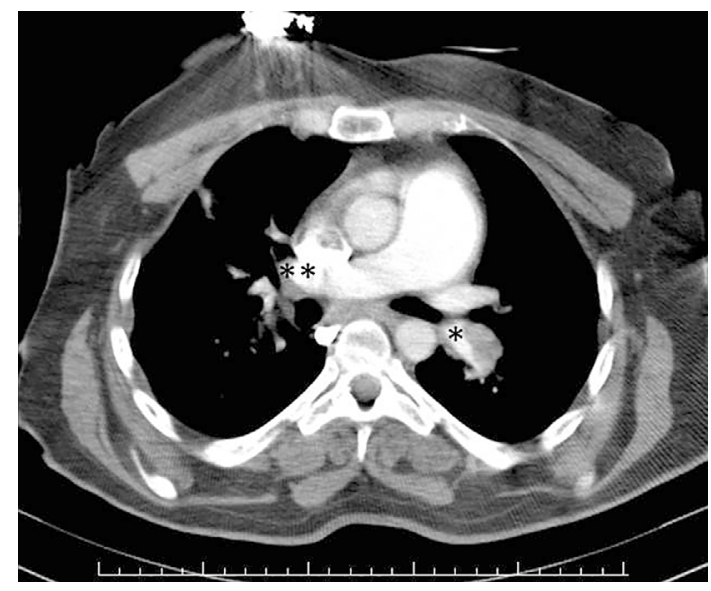

Figure 2. Thorax CT revealing thrombi in the brunches of the pulmonary arteries (*: left lower lobe pulmonary artery, **: right upper lobe pulmonary artery).

discharged from the hospital on 6-month warfarin treatment. At 8 weeks after her discharge, thorax CT was performed and revealed clear pulmonary arteries free of any thrombi (Fig. 3, 4). The patient is being followed under anticoagulant therapy and currently remains asymptomatic.

\section{Discussion}

Vein operations are among the procedures carrying the lowest risk of all surgical interventions (5). PTE is a wellknown complication of major surgery, however, it is not always appreciated that it can occur even after minor interventions such as varicose vein surgery $(5,6)$. In a study including 599 patients for complications associated with varicose vein surgery, Critchley at al. showed that the incidence of VTE was $0.5 \%$, whereas the incidence for PTE was $0.15 \%$ (2). The risk of a thromboembolism following varicose vein surgery depends on various factors such as coagulation disorders, which often go unnoticed until the first event occurs, age and the presence of concomitant diseases, and the extent and duration of the surgical intervention. It is generally accepted that small saphenous vein (SSV) surgery carries a greater thrombotic risk than great saphenous vein (GSV) surgery (5). It has also been shown that superficial vein thrombosis (SVT) can propagate into the deep veins in $7-44 \%$ of cases, leading to deep venous thromboembolism (DVT) and potentially concurrent PTE $(7,8)$. The progression of superficial phlebitis was investigated in 2003 in the Stenox study (9), which showed that this process persists for at least 3 months with a rebound effect after the withdrawal of low-molecular-weight heparin after 10 days. In fact, patients treated with a much cheaper oral nonsteroidal antiinflammatory agent eventually showed identical results. In the 2010 Calisto Study, antithrombotic prophylaxis was extended to 45 days and a clear advantage was demonstrated (10). However, it remains unclear in regard to the optimal timing to initiate prophylactic anticoagulants following varicose vein operation, and recent guidelines do not 


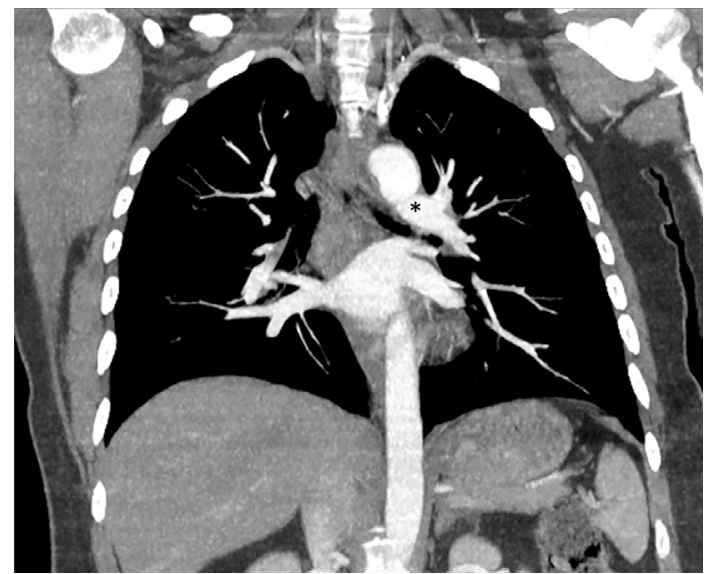

Figure 3. A coronal slice of contrast-enhanced thorax CT showing clearance of thrombi from the left main pulmonary artery (*: left pulmonary artery).

recommend prophylaxis with anticoagulants in this setting (11). Our patient had not been on any anticoagulants at presentation.

Our patient presented with severe shock leading to cardiac arrest. Approximately 5-10\% of patients with PE have an unstable hemodynamic status which may lead to shock $(12,13)$, and such patients have a 15-60\% higher mortality rate compared with patients without a compromised hemodynamic status (12-15). It is therefore is very important to make a differential diagnosis immediately in patients with shock to initiate target therapy. Our patient presented with chest pain. There were no ischemic changes on her electrocardiogram. Aortic dissection was excluded because a normal aorta was found on contrast-enhanced thorax CT scans. There were no clinical or laboratory findings to support the diagnosis of either intoxication or sepsis that might lead to shock. Due to the patient's history of recent surgery, sternal chest pain on presentation, development of cardiac arrest and findings of pulmonary hypertension and dilated right heart chambers on bedside echocardiography our strong prediagnosis was an acute PE (5). Our diagnosis was confirmed by contrast-enhanced CT scans revealing thrombi in the main pulmonary arteries.

The only target treatment available for our patient with an acute PE leading to the shock status was thrombolytic therapy. Currently, thrombolytic therapy for PTE remains controversial. Active cardiopulmonary resuscitation (CPR) is clearly not a contraindication for thrombolytic therapy. In a study including 6 massive PTE patients who were given thrombolytic therapy following CPR, it was determined that thrombolytic therapy is a life-saving treatment option for such group of patients (16). In a recent study including 34 massive PTE patients, it was concluded by the authors that thrombolytic therapy given concurrently with CPR is both effective and safe (17). In our case, alteplase was given after nontraumatic CPRs, and no complication was observed and her clinical status improved dramatically. In the literature, there are only 2 case reports of massive PTE after varicose

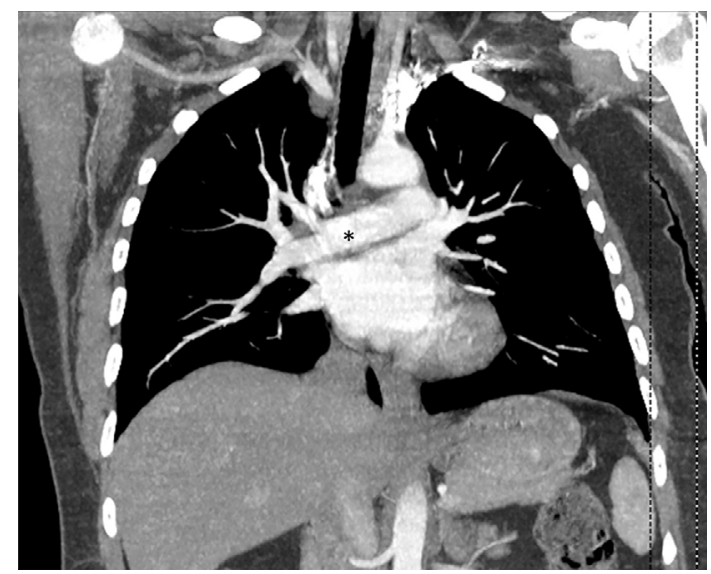

Figure 4. A coronal slice of contrast-enhanced thorax CT showing clearance of thrombi from the right main pulmonary artery (*: right pulmonary artery).

vein surgery. Our case is important because it is the third case reported in the literature which demonstrated the rapid recovery of a massive PTE patient due to successful thrombolytic therapy administered after 2 non-traumatic CPRs.

In conclusion, it should be kept in mind that massive PTE even after minor surgical procedures such as varicose vein surgery may occur. Massive PTE is a life-threatening disease and the risk of death is greater when it is accompanied by cardiac arrest. Therefore perforing thrombolytic therapy after CPR in such patients with high mortality rates can be a lifesaving treatment modality.

The authors state that they have no Conflict of Interest (COI).

\section{References}

1. Rosendaal FR. Risk factors for venous thrombotic disease. Thromb Haemost 82: 610-619, 1999.

2. Critchley G, Handa A, Maw A, Harvey A, Harvey MR, Corbett CR. Complications of varicose vein surgery. Ann R Coll Surg Engl 79: 105-110, 1997.

3. Van Rij AM, Chai J, Hill GB, Christie RA. Incidence of deep vein thrombosis after varicose vein surgery. Br J Surg 91: 1582-1585, 2004.

4. Özkaynak B, Kayalar N, Polat A, et al. Thrombolytic treatment of massive pulmonary embolism as a complication of varicose vein surgery. JAREM 1: 26-27, 2011.

5. Oesch A. Thrombosis and pulmonary embolism risk in patients undergoing varicose vein surgery. Phlebolymphology 20: 96-100, 2013.

6. Wu B, Zhao GJ, Liang H, Lu ZQ, Qiu QM, Lu YR. Thrombolytic therapy for cardiac arrest due to pulmonary embolism after varicose vein surgery. Intern Med 51: 1899-1902, 2012.

7. Leon L, Giannoukas AD, Dodd D, Chan P, Labropoulos N. Clinical significance of superficial vein thrombosis. Eur J Vasc Endovasc Surg 29: 10-17, 2005.

8. Van Langevelde K, Lijfering WM, Rosendaal FR, Cannegieter SC. Increased risk of venous thrombosis in persons with clinically diagnosed superficial vein thrombosis: results from the MEGA study. Blood 118: 4239-4241, 2011.

9. Superficial Thrombophlebitis Treated by Enoxoparine Study Group. A pilot randomized double-blind comparison of a low- 
molecular-weight heparin, a nonsteroidal anti-inflammmatory agent and placebo in the treatment of superficial vein thrombosis. Arch Intern Med 163: 1657-1663, 2003.

10. Decousus H, Prandoni P, Mismetti P, et al; CALISTO Study Group. Fondaparinux for the treatment of superficial-vein thrombosis in the legs. N Engl J Med 363: 1222-1232, 2010.

11. The Task Force for the Diagnosis and Management of Acute Pulmonary Embolism of the European Society of Cardiology (ESC) Eur Heart J 35: 3033-3080, 2014.

12. Darze ES, Latado AL, Guimarães AG, et al. Incidence and clinical predictors of pulmonary embolism in severe heart failure patients admitted to a coronary care unit. Chest 128: 2576-2580, 2005.

13. Goldhaber SZ, Visani L, De Rosa M. Acute pulmonary embolism: clinical outcomes in the International Cooperative Pulmonary Em- bolism Registry (ICOPER). Lancet 353: 1386-1389, 1999.

14. Marshall PS, Matthews KS, Siegel MD. Diagnosis and management of life-threatening pulmonary embolism. J Intensive Care Med 26: 275-294, 2011.

15. Konstantinides SV. Massive pulmonary embolism: what level of aggression? Semin Respir Crit Care Med 29: 47-55, 2008.

16. Ruiz-Bailén M, Aguayo-de-Hoyos E, Serrano-Córcoles MC, et al. Thrombolysis with recombinant tissue plasminogen activator during cardiopulmonary resuscitation in fulminant pulmonary embolism. A case series. Resuscitation 51: 97-101, 2001.

17. Dirican A, Ozkaya S, Atas AE, Ulu EK, Kitapci I, Ece F. Thrombolytic treatment (alteplase; rt-PA) in acute massive pulmonary embolism and cardiopulmonary arrest. Drug Des Devel Ther 8: 759-763, 2014

(C) 2016 The Japanese Society of Internal Medicine http://www.naika.or.jp/imonline/index.html 